\title{
Gianni Mombello, Les avatars d'une facétie de Cicéron
}

\section{Paola Cifarelli}

\section{(2) OpenEdition}

\section{Journals}

\section{Edizione digitale}

URL: http://journals.openedition.org/studifrancesi/8845

DOI: 10.4000/studifrancesi.8845

ISSN: 2421-5856

\section{Editore}

Rosenberg \& Sellier

\section{Edizione cartacea}

Data di pubblicazione: 1 octobre 2008

Paginazione: 437

ISSN: 0039-2944

\section{Notizia bibliografica digitale}

Paola Cifarelli, «Gianni Mombello, Les avatars d'une facétie de Cicéron», Studi Francesi [Online], 155 (LII

II) | 2008, online dal 30 novembre 2015, consultato il 11 janvier 2021. URL: http://

journals.openedition.org/studifrancesi/8845 ; DOI: https://doi.org/10.4000/studifrancesi.8845

Questo documento è stato generato automaticamente il 11 janvier 2021.

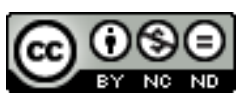

Studi Francesi è distribuita con Licenza Creative Commons Attribuzione - Non commerciale - Non opere derivate 4.0 Internazionale. 


\title{
Gianni Mombello, Les avatars d'une facétie de Cicéron
}

\author{
Paola Cifarelli
}

\section{NOTIZIA}

GIANNI MOMBELLO, Les avatars d'une facétie de Cicéron, in Grant risee? The Medieval Comic Presence - La Présence comique médiévale. Essays in Memory of Brian J. Levy, Edited by Adrian P. TUDOR and Alan HINDLEY, Turnhout, Brepols, 2006 («Medieval Texts and Cultures of Northern Europe», 11), pp. 225-246.

1 Il punto di partenza di questo studio è un aneddoto ciceroniano, presente nel De Oratore, a proposito di un marito, vedovo di una moglie morta impiccata ad un fico, ed un amico che chiede un rametto di quest'albero per poterlo piantare nel suo giardino; lo scopo è facile da indovinare. G. Mombello, di cui si rimpiange la grande erudizione, va alla ricerca di nuove attestazioni di questa storiella, tanto nella letteratura classica, mediolatina ed umanistica quanto in quella mediofrancese, rappresentata soprattutto dal Violier des histoires romaines, i Ditz des sages hommes di Guillaume Tardif e le Fantasies de Mere Sote di Pierre Gringore, oltre al Grand Parangon des nouvelles nouvelles di Nicolas de Troyes. 